\title{
NICANOR PARRA, FLÂNEUR EN CHILLÁN
}

\author{
NICANOR PARRA AND THE FLÂNEUR IN CHILLÁN
}

\section{MANUEL JOFRÉ}

\section{RESUMEN}

Luego de visualizar la posición de la antipoesía de Nicanor Parra en el sistema poético chileno, se comentan los primeros textos poéticos del antipoeta, desde 1935 en adelante, tanto narrativos como líricos, explorando el proceso de creación hacia la revolución antipoética que se concretaría en 1954 con Poemas y antipoemas, pero estableciendo que el primer antipoema es de 1939, y clarificando las diversas exploraciones entre 1935 y 1939.

Palabras clave: Nicanor Parra, antipoesía, flâneur, cronotopo, Chillán, Chile.

\section{ABSTRACT}

After visualizing the position of the antipoetry of Nicanor Parra in the Chilean poetic system, from the first texts of the antipoet, in 1935, both narrative as well as lyrical texts, we explore the creative process leading to the antipoetic revolution that will become consolidated with Poemas y antipoemas. We establish the first antipoem in 1939, clarifying the poet's diverse explorations between 1935 and 1939.

Keywords: Nicanor Parra, antipoetry, flâneur, chronotope, Chillán, Chile.

Recibido: 20.07.14. Aceptado: 06.10.14.

* Ph.D. Profesor Titular y de Excelencia Universidad de Chile. Santiago, Chile. Director Fundación IberoAmericana. Correo: jofremanuel@gmail.com 
$\mathrm{E}$

STA ES LA CELEBRACIÓN de un homenaje, la experiencia carnavalesca del entusiasmo, una comunidad que se reúne porque le importa la vida de un hombre y su creación. Esta es una fiesta antipoética que saluda a uno de los nuestros que ha logrado llegar con la palabra muy lejos en una exploración solitaria y profunda.

En esta ocasión interesa saber qué significa hablar en el nombre de Parra, diciendo con ello que el nombre de Parra contiene, oculta y/o devela un alto número de problemas literarios y discursivos que vale la pena dilucidar.

El mundo de Parra es un mundo sin dios. Un dios sin mundo. Aunque la palabra Dios aparezca o el hablante dialogue con él, aparentemente. En cuatro de los cinco grandes poetas chilenos está la tragedia de un dios no mencionado, que carece de un mundo. Esto pasa con Neruda, Huidobro, de Rokha, y con Parra.

Obviamente, el mundo descrito por estos poetas es parte modeladora de la primera fase latinoamericana del espacio postmoderno, en el siglo XX, aquello que inexorablemente acontece desde la primera manifestación de la vanguardia latinoamericana en poesía, con la emergencia del creacionismo, en la segunda década del siglo pasado, gracias a la palabra teórica y poética de Huidobro.

Baste decir que todos los poetas posteriores a Parra son antipoéticos. Han asimilado su apertura, su tono, sus temas, sus formas, su mirada, su escritura. Aparte de los innumerables poetas que primero Neruda marcó discursiva y poéticamente mediante sus numerosas y sucesivas poéticas, se puede constatar que no hay seguidores de Neruda en Chile, en cuanto lenguaje estético, en cuanto escritura poética (con la excepción de algunos poemas de Raúl Zurita). Lo contrario sucede con la antipoesía de Parra pues no hay escritura poética en Chile que no le deba a su palabra.

No se puede hablar de la poesía de Parra sin aludir necesariamente al sistema poético chileno, del cual es parte, y el cual es lenta y parcialmente explorado por la crítica. Hay buenas contribuciones interpretativas a algunas obras de algunos poetas chilenos principales, y hay hasta ahora abordajes a una parte de la escritura de estos poetas.

Admitiendo que cinco están en el centro, hay además una abundante periferia de poetas maduros (de los 40 a los 80 años) de primera magnitud, y hay también poetas jóvenes (de menos de 40 años), no canonizados, que han realizado un gran aporte.

Se podría decir que todos los poetas posteriores a Parra desarrollan al- 
guna línea poética que Parra transformó en su momento. A diferencia de lo que piensa Ignacio Valente, el sistema poético chileno ha recibido profundos estudios renovadores en los últimos años, los cuales han sido presentados en congresos internacionales de poesía y literatura organizados en Chile y fuera del país.

Los materiales desintegrados de estas contribuciones parciales están en actas publicadas institucionalmente, en libros que reciben las ponencias presentadas, en revistas especializadas en estudios literarios (hay una docena en Chile) y por cierto, en artículos divulgados a través de Internet.

El presente momento, en que la poesía de Parra alcanza su apogeo, cuya fuerza no se ha detenido nunca antes, se caracteriza por el alto número de estudios monográficos centrados en la obra escrita de una treintena de poetas chilenos, de alta calidad pero de escasa difusión, focalizados mayormente en obras específicas.

Falta todavía, por cierto, un mayor trabajo comparativo, pero el textualismo funcionalista intrínseco imperante en los estudios literarios no ha permitido dar un paso más decidido al estudio discursivo, histórico, cultural e intertextual. Estas son las limitaciones nacionales para escribir nuestra historia literaria.

La palabra poética de Parra es un mundo poético que frente a la inestabilidad del presente y a la incertidumbre acumulada, más el desencanto y la frustración, logra esbozar una respuesta muy compleja, polisémica, ambigua, irónica, no capturada aún por completo.

\section{LOS ORÍGENES DE LA ANTIPOESÍA}

Una investigación reciente, en curso, de la obra primera de Parra, acerca del periodo formativo de Nicanor, realizada por Ernesto Pfeiffer, de la Universidad de Chile, revela el carácter itinerante de la vida de los Parra, moviéndose por San Fabián de Alico, Chillán, Lautaro, Santiago (primera residencia, en 1919, incluso antes que Neruda, cuando Nicanor tenía sólo 5 años de edad).

Esta tesis, de 218 páginas, incluyendo Bibliografía, fue dirigida por quien escribe estas páginas. Se trata de un extraordinario estudio y un exhaustivo análisis de la obra escrita del joven Nicanor Parra, desde que tenía 21 años de edad hasta la formulación de los antipoemas, cuando el ya antipoeta frisaba los 44 años. La tesis se titula "La primera etapa de la poesía de Nicanor Parra (1935-1948): Hacia la revolución antipoética”. 


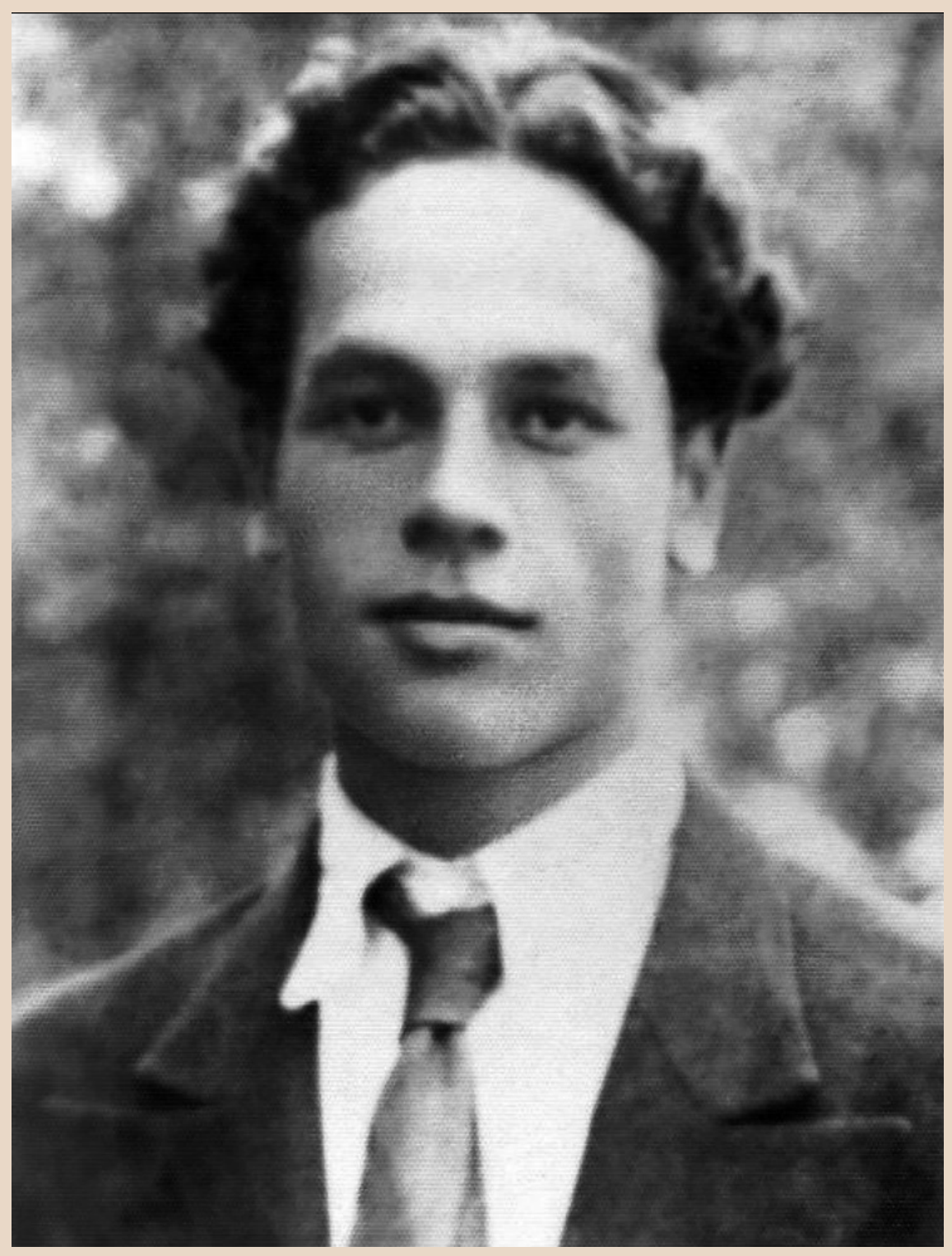

N. Parra en su época de estudiante. 
Esta tesis se escribe en un momento en que el poeta de Las Cruces llega a los 99 años de edad y ha alcanzado casi todos los premios occidentales a la creación literaria, con la sola excepción del Premio Nobel de Literatura, que debió haber recibido hace varios años.

Los catorce primeros años de la escritura parriana (1935-1948) vienen a llenar un vacío sorprendente en la historia de la gran poesía chilena. Aunque la primera tesis universitaria sobre Parra data de 1954, realizada en la Universidad de Chile por el poeta y académico Sergio Hernández, la producción primera del poeta de San Fabián de Alico no había sido examinada con detalle, prolijidad y atento análisis en ninguna ocasión previa.

Posteriormente, en esta tesis se divide el periodo bajo estudio en cinco etapas sucesivas y graduales, comenzando, en primer lugar, por el estudio de la narrativa parriana, expresada en dos cuentos, donde ya hay gestos antipoéticos de variada índole. También hay aquí una obra narrativa-dramática de Parra, en el inicio de una búsqueda y creatividad no vista previamente en la literatura chilena. Por último, se analizan los tres primeros poemas dados a conocer por el antipoeta, donde ya se aprecian rasgos surrealistas, absurdos y antipoéticos. Se trata de "Sensaciones", de 1935.

Entre 1935 y 1948, Parra da a conocer preliminarmente dos cuentos, un drama y 55 poemas ( 25 de los cuales están en Cancionero sin nombre, de 1937). En este período, los relatos "Gato en el camino" y “Tomás, el ayudante del otoño" son un importante origen de la escritura parriana, no suficientemente examinados ni considerados por la crítica.

Estos primeros textos antipoéticos son mejor comprendidos desde la consideración bajtiniana de que la poesía se encuentra bajo el signo de la novelización, cuyo primer signo es la prosificación del ente lírico, que es lo que aquí acontece. Estos textos narrativos son surrealistas, superrealistas, fantásticos, rupturistas, vanguardistas e ironizadores de la tradición literaria.

Este primer periodo formativo de Parra, poco estudiado, muestra claramente la vinculación de la tradición culta con la oralidad, lo coloquial y lo conversacional, que estarán posteriormente en el centro de la definición lingüística del antipoema.

Posteriormente, se aborda la producción en verso más moderna y de carácter lírico narrativo, la cual culmina con la publicación de Cancionero sin nombre, en 1937. Esta segunda etapa ha sido reductivamente vista como si fuera una mera imitación o la influencia de Federico García Lorca por la crítica, pero eso cambiará radicalmente con las nuevas lecturas propuestas por Pfeiffer (2014). 
En efecto, lo que se construye es un "anticancionero". El capítulo se abre al examen de la influencia de García Lorca en diferentes escrituras poéticas chilenas, sección que es seguida por un exhaustivo estudio comparativo de Romancero gitano con respecto a Cancionero sin nombre. Finalmente, luego de explicar el título de la obra de Parra y de examinar atentamente tres poemas del período estudiado, se concluye en el desplazamiento de lo lírico hacia su opuesto.

\section{LOS PRIMEROS CRONOTOPOS DE LA OBRA PARRIANA}

Un camino que no se ha intentado con respecto a la obra de Parra es percibir la presencia y arquitecturación de diversos cronotopos en los poemas mismos. Una primera percepción daría los siguientes resultados:

El cronotopo popular folklórico es una primera dirección evidente en cuanto la incorporación de temas cotidianos, la presencia de lo social, las formas populares (como el romance, el esquinazo o la paya).

Un segundo cronotopo presente era naturalmente infaltable: lo autobiográfico, que emerge de diversas modalidades imbricado con los otros cronotopos. La vida propia, como primera materia a la cual echar mano.

Finalmente, un tercer cronotopo detectable es lo idílico, es decir, la relación armónica que representa el mundo natural en un mundo todavía organizado mediante la escritura moderna rimada. Cabe señalar la ausencia del tema amoroso, a diferencia de los otros grandes poetas chilenos.

El próximo momento de la creación parriana, tampoco debidamente aquilatado por la crítica, es todo un profundo y amplio proceso de experimentación, búsqueda, selección y depuración de formas poéticas tradicionales, que siguieron a la publicación de Cancionero sin nombre.

Luego de retomar la narrativa breve parriana, se abordan en la tesis de Pfeiffer las lecturas de los casi desconocidos romances patrióticos de Parra. Luego se prosigue con el paralelismo establecido explícitamente entre los cantos cotidianos y los cantos paralelos, tampoco previamente estudiados.

Todo esto significa que el espacio presente en los primeros poemas de Parra es mayormente social y popular, con miradas propias subjetivas que son protoantipoéticas (ya desde "Sensaciones", los tres primeros poemas de 1935), donde la sociedad degradada se contrapone a la armonía de la naturaleza (Jofré, 2002).

Uno podría decir que se mantiene una forma poética moderna, antigua, versificada, mientras que desde el inicio los contenidos han ido cambiando, 
con una nueva sensibilidad. Esto hace que se perciba pronto, en la primera producción parriana, un mundo que no calza bien, la gradual desintegración de la realidad, la pre-eminencia de los procesos transformacionales, el predominio del humor, la emergencia de lo irónico, un decir fantasioso.

Con la publicación de la antología de 8 nuevos poetas chilenos (Sociedad de Escitores de Chile, 1939) se alcanza un nuevo estadio, que incluye experimentaciones con lo folklórico, poemas trágicos coyunturales, poesía local de alabanza citadina, sonetos romanceados, la utilización de formas clásicas cultas españolas, el premonitorio encuentro con Gabriela Mistral, el poema didáctico, y finalmente, la creación del que será el primer antipoema que transitará a Poemas y antipoemas, de 1954.

"Sinfonía de cuna" sigue siendo el primerísimo antipoema, con su interculturalidad, su historia absurda, su ironía, su ritmo infantil, desde la primera versión (no completa) de 1939. En efecto, es una versión diferente, más breve, que la que se conocería posteriormente. Pero eso no excluye el hecho innegable, no declarado, que el primer antipoema sea de 1939, con claros antecedentes antipoéticos en las publicaciones en prosa y en verso de 1935. Este es un dato fundamental para la historia del sistema poético chileno y su relación con la poesía latinoamericana y occidental.

Finalmente, se analiza la poesía política y combatiente del primer Parra. De más está decir que la crítica de la poesía chilena no había dado cuenta nunca de esta variedad y su significación en el proceso creativo de Parra y en la gradual conformación de la revolución antipoética que se conformaba a fines de los cuarenta. El componente de crítica social y de poesía altamente política no ha estado en verdad nunca ausente en la producción parriana.

A continuación viene un punto alto dentro del desarrollo poético. Se trata de una culminación poética y la adquisición definitiva de una estructura versicular, consistente en la utilización del verso endecasílabo como síntesis poética. En esto Pfeiffer logra sus mejores aciertos.

Se estudia aquí especialmente la antología de Tomas Lago, Tres poetas chilenos, y se analizan estos tres poemas que transitarán a Poemas y antipoemas: "Se canta al mar", "Hay un día feliz" y "Es olvido". Luego de descubrir el carácter híbrido de estos poemas (poéticos y antipoéticos, modernos y postmodernos), se concluye la investigación con una lectura de otro conjunto de poemas que había sido dejado de lado, los "Ejercicios respiratorios".

El último momento de la escritura de Parra en el proceso de modelación y modulación de los antipoemas está tratado en la sección final de la tesis 
que comentamos. Se accede ahora en plenitud a una madurez antipoética y a la ironía como dispositivo discursivo central. Para evidenciar esto, se estudian tres grandes y complejos antipoemas: "La trampa" "Los vicios del mundo moderno" y "La víbora".

En algunos de estos poemas comentados se percibe, inicialmente, un cierto desfase entre la forma y el fondo, entre la expresión arcaica con una sustancia humana sorpresiva disonante y nueva. La perfecta integración entre ambas esferas acontecerá a partir de 1948, cuando Nicanor escriba los primeros antipoemas.

La tesis concluye resaltando el primer texto de Parra que es un manifiesto teórico, estético y literario, incluido en 13 poetas chilenos, y en seguida, clausura la investigación con la transcripción de una carta inédita de Jorge Millas, del 22 de julio de 1949, dirigida al antipoeta.

\section{CHILLÁN, SIEMPRE CHILLÁN}

Nicanor Parra Sandoval nace en San Fabián de Alico, según el certificado de nacimiento, el 5 de septiembre de 1914. El año de la Primera Guerra Mundial. Sin embargo, según sus declaraciones personales a nosotros, la verdadera fecha de su nacimiento fue el 4 de septiembre de 1914.

Luego de un corto paso por Chillán (primera estadía, en casa de los abuelos, posiblemente en 1918), la familia se traslada a Lautaro, en fecha no precisada y de allí, en 1919, se establecen por primera vez en Santiago, hasta 1921, cerca de calle y puente Manuel Rodríguez. Luego de dos años en la capital, retornan a Lautaro, donde Nicanor Parra permanecerá hasta 1927, estudiando sus primeras letras en la ciudad sureña.

La segunda estadía en Chillán es entre 1927 y 1932. El joven Nicanor llega de 12 años de edad y es estudiante en el Liceo de Hombres de Chillán, cursando humanidades hasta el quinto año. Vive en el barrio de Villa Alegre, también llamado posteriormente Ultra Estación. Aunque de este período no subsiste ningún escrito, sus primeras composiciones infantiles $y$ juveniles debieron generarse en estos años.

En 1932 se traslada a Santiago y el sexto año de humanidades lo cursa ya en la capital, en el Instituto Nacional Barros Arana. Al año siguiente, en 1933, ya ha ingresado al Instituto Pedagógico de la Universidad de Chile, a estudiar Pedagogía en Matemáticas y Física. Simultáneamente, trabaja como inspector en el INBA.

En 1937 se gradúa como profesor y retorna a Chillán, en su tercera y 
última estadía en esa ciudad, donde enseñara y será inspector del Liceo de Hombres. Permanecerá en Chillán hasta unos días después del 24 de enero de 1939, fecha del gran terremoto, para volver a Santiago.

En síntesis, en la segunda década del siglo XX Parra ve Chillán desde la mirada fugaz de un niño, en la tercera década ya posee una mirada juvenil de un estudiante y en la cuarta década ya es un joven profesional y docente. Es este último período el que nos interesa en esta ocasión.

Como es claro en la argumentación que se irá desarrollando, ya desde el principio de su escritura latía en las palabras de Parra el futuro de la sociedad occidental. Parra no sólo estaba atento a las formalidades externas sino que a las contradicciones profundas, culturales, sociales y políticas. No le interesaban las homologías o los ordenes analógicos sino que las paradojas, los desfases, las emergencias de lo reprimido.

Situado en una amplia tradición romántico-simbolista, abría la puerta al grotesco, al feísmo, al claroscuro, al surrealismo, dejando atrás la idea de lo clásico idealizado. Su escritura sería materialista desde el comienzo, como en De Rokha, porque el marco donde se alojaba no era la poética del idealismo clásico sino que del realismo grotesco, que se podría definir como la suma de lo armónico más lo inarmónico, en una renovada combinación.

Como hemos argumentado anteriormente, Parra anunciaba con la revolución antipoética la venida de la posmodernidad, como período cultural del capitalismo tardío, tal como ha propuesto Jameson. Y lo hizo hasta en las últimas clases que enseñó en la Escuela de Ingeniería o más precisamente en la Facultad de Ciencias Exactas y Matemáticas de la Universidad de Chile, donde utilizaba el artículo de Foster acerca de lo posmoderno, realizando una lectura atenta y comentada de él.

Chillán fue un espacio privilegiado para la primera reflexión poética parriana. Su permanencia como profesor de matemáticas, entre 1937 y 1939 , le permitió a Parra distanciarse del mundo lárico, naturalista y regionalista. Sus poemas de la última parte de la década de los 30 evidencian una insistente búsqueda en lo histórico, lo folklórico, lo popular, lo surrealista y el romance.

Su creatividad y habilidad consistió en no plegarse nunca al arcaísmo neoindigenista de Gabriela Mistral, ni al simbolismo surrealista nerudiano (salvo una sola excepción), ni al creacionismo cósmico huidobriano, ni al tremendismo político y popular de De Rokha, todos ellos discursos poéticos imperantes y vigentes dentro y fuera de Chile con gran potencia en los años 30 del siglo pasado. 


\section{VUELTA A LOS ORÍGENES DE LA ANTIPOESÍA}

La primera fase de este proceso de filtración selectiva y búsqueda de un lenguaje y un mundo poético propio, por cierto que aconteció en Santiago, entre 1932 y 1937. La Revista Nueva, en su número 1, de 1935, publicada en Santiago por Jorge Millas, Carlos Pedraza y Nicanor Parra, incluía, simultáneamente, un relato "Gato en el camino" y "Sensaciones" (que eran tres poemas: "Ensueño", "Nostalgia" y "Silencio"). Nuestra argumentación es que el origen de la antipoesía está al mismo tiempo en la narrativa breve $\mathrm{y}$ en los poemas.

"Gato en el camino" es un relato absurdo, fantástico, surrealista, superreal, pero al mismo tiempo paródico, americanista, crítico y antipolítico. Es realismo mágico puro, del garcimarquiano que brotaría años más tarde. Pero los poemas de "Sensaciones", que tampoco han sido analizados con el detalle que requieren pues son también composiciones irónicas, surreales, absurdas, fantásticas, ambiguas.

Estos poemas no se parecen al período surrealista nerudiano ni a la poesía previa de nadie. No hay rima ni metro de ningún tipo. Y las imágenes lo dicen todo: "volteretas de cien pejerreyes" y "gallina de cristal", en "Ensueño", engarzadas en el cronotopo del viaje y el cronotopo del camino. El "Ensueño" es justamente lo contrario. Ya se insinúa el paseo del flâneur, actitud que se perfeccionará años más tarde, de regreso en Chillán.

La polisemia, el doble sentido de estos poemas, el grotesco de las imágenes, el yo que estalla, hablan del espacio de Chillán recapturado. No es la ciudad de Santiago la presente. En "Nostalgia" hay una antinostalgia y un retrato paródico de la infancia, con una imagen final: "Algunas veces me brinca un renacuajo en los párpados" e incluso el cronotopo autobiográfico está profundamente alterado. Este mundo es antilárico. El cronotopo idílico de la infancia está totalmente revertido.

En "Silencio" hay nuevamente la perdida de la armonía, el quiebre de la infancia, el grotesco de "las moscas zumbando", todo lo cual permite concluir que ya están los momentos básicos del antipoema, la construcción de una situación, luego la modelación de un género o formato que contiene esta historia, a lo que le sucede una tensión entre lo cotidiano y lo sublime (o lo superreal), y donde se revierte lo inicial, concluyéndose en una síntesis irónica, una desconstrucción antipoética.

No trabajaremos aquí "El ángel (Tragedia novelada. Fragmento)", obra híbrida e intergenérica aparecida en el número 2 de la Revista Nueva, de 1936, ni tampoco Cancionero sin nombre (de 1937) que es una parodia de 
García Lorca, plena de absurdo, delirio, desaparición de lo lírico, emergencia del cronotopo folklórico (el huaso chileno). Tampoco comentaremos el segundo relato publicado por Parra, titulado "Tomás o el ayudante del otoño", en La Aurora de Chile, No II, de 1939, donde nuevamente se revierte el cronotopo autobiográfico.

Todos estos textos aquí mencionados figuran en el volumen I de las Obras completas (2006) en la sección "Los trapos al sol" (561-585), y también en las "Notas" (a partir de la página 907) del mismo volumen (especialmente páginas 999-1018).

\section{EL FLÂNEUR Y LOS CRONOTOPOS AUTOBIOGRÁFICO Y DEL CAMINO}

Pero sí nos interesa comentar diversas publicaciones aparecidas a lo largo del año 1939, que fueron planeadas, compuestas y escritas en Chillán. El poeta tiene 24 años cuando vive en Chillán. Lo más importante es que el hilo conductor es el continuo movimiento del hablante por diversos lugares, como un flâneur, en conjunción con un fuerte ánimo autodefinitorio y autocaracterizador que no ha sido notado antes, en un obvio cronotopo autobiográfico que se conjuga con el cronotopo del camino.

El joven poeta Parra es un flâneur en varios sentidos. Es un paseante por Chillán, por cierto, pero también un explorador de diversas formas poéticas. Hay dos sentidos pues: uno físico y otro poético. En el caso material o geográfico, el hablante vagará sin rumbo por la ciudad, como un moderno espectador urbano; pero en el sentido intelectual, el flâneur visitará, en un aprendizaje, distintas formas de ver y de decir, organizaciones poéticas genéricamente distintas, construyendo gradualmente una filosofía de pensar y de vivir.

La línea del género romance explorada por Parra en Cancionero sin nombre que revierte los sentidos del Cancionero gitano de García Lorca (1973 [1928])asume otra dirección, también diegética, con los romances históricos aparecidos en Panorama y color de Chile, una antología realizada por Antonio Roco del Campo (1939). Lo destacable es el sentido prosificador de la forma poética utilizada, rasgo que no ha sido notado anteriormente en toda su profundidad. Esta antología busca lo que Gramsci llamaría "lo nacional y popular".

El poema de Parra se titula "Aventura de Manuel Rodríguez" y lo central para esta lectura es que lo histórico, que es la nueva orientación asumida,
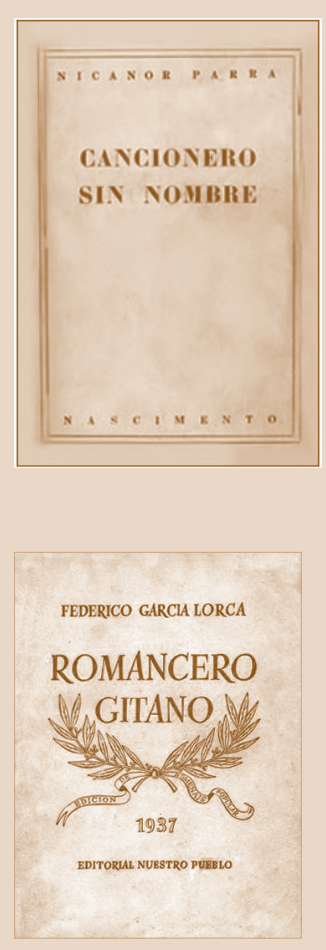

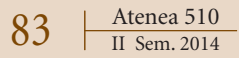


aparece en la figura de Manuel Rodríguez, concretada en el cronotopo del camino. Se trata de una experiencia que le acontece al patriota chileno, que es parte del gran ciclo narrativo de la formación del héroe, en conjunción con el cronotopo de la aventura.

El otro poema de Parra aquí es "Historia de José Miguel Carrera", lo que confirma el ánimo y la búsqueda por lo histórico. Nuevamente lo estructurador de la experiencia de Carrera está dado por el cronotopo del camino, es decir, lo que solía denominarse el motivo del viaje.

Un último rasgo necesario de destacar es la predilección juvenil de Parra por nominar sus composiciones con los géneros discursivos y literarios a las cuales éstas pertenecen. Ello se revela en la palabra "aventura" (como en novela de aventuras"). Antes lo ha hecho con Cancionero... y con "El ángel. Tragedia novelada...”. Lo mismo hace con "Historia de José Miguel...", donde nuevamente el formato o género es revelado. Ya vendrán otras nominaciones más.

\section{9: EL FLÂNEUR QUE RECUERDA EL PASADO INMEDIATO}

El mismo año decisivo de 1939 aparecen publicados otros dos poemas, esta vez en la revista Atenea, de la Universidad de Concepción. En el No 168 aparece "Cantos cotidianos", de junio de ese año. Se trata de dos poemas, "Sinfonía" (donde dice: "soy el mismo/ solitario estudiante de mi pueblo" y "Nocturno" (cuyo estribillo reformulado dice "He de partir"). Ambos son poemas de la cultura letrada, de la alta cultura, y asumen la línea del poema simbolista lírico. La narratividad anterior de los romances ha disminuido. Los cantos son un género (desde Petrarca) y ambos poemas aluden a lo musical y también a los géneros o formatos implicados (música mayor y música de noche).

Hay que destacar que el cronotopo autobiográfico se materializa en "Sinfonía" con un constante intento autodefinitorio, donde comienza la autorreferencia como corazón, como corsario ("vagabundo corcel aventurero), que continuará posteriormente. En "Nocturno", aunque está la presencia final de la muerte, hay una claridad imperante. Este poema une nuevamente el cronotopo del camino, donde se encuentran las experiencias vitales con el cronotopo autobiográfico. Finalmente, aparecen seriamente ángeles y arcángeles, figuras que serán decisivas para el proceso de configuración de lo antipoético.

La idea de paralelismo, no notada en ningún lugar anteriormente (Can- 
cionero de Lorca y Cancionero de Parra, los dos romances históricos, los dos cuentos surrealistas, los dos cantos cotidianos), es fuerte en todas estas composiciones, donde lo binario tiene su raíz en la tradición explorada (canción, romancero, historia, surrealismo, folklore, lírica), la cual es asumida pero transformada. El binarismo también alude a la convergencia de lo culto y lo popular, y por cierto a la realidad cotidiana y lo superreal que late bajo ella. No hay que olvidar que estos cantos son "cotidianos", una palabra siempre utilizada para describir la antipoesía parriana.

Este paralelismo binario viene a reconfirmarse con la publicación de los "Cantos paralelos" (nótese la auto-ironía) en el número siguiente de la revista Atenea No 174, de diciembre de 1939. Se trata de cuatro poemas. "Fuga", el primero de ellos, trae de regreso los ángeles y las expresiones coloquiales ("yo sé bien lo que digo") y nuevamente la presencia de la muerte, considerado un hecho cotidiano ("esta doliente moda"). La oralidad, los ángeles y la muerte ("mil veces moriré mas mil son pocas") siguen presentes en el segundo poema ("Preludio"). Ambos aluden a géneros musicales y por tanto, hay que notar, por primera vez, no sólo la alusión a los formatos o géneros en los títulos sino que la impronta musical en estas primeras obras.

El tercer poema, "Soledad primera", como los anteriores, contiene ya elementos antipoéticos (corbatas, vidrios, hierros) y las autodefiniciones continúan, con variadas menciones al sujeto que es un "marino" o un "bandido". Reaparece el ángel. Todo es un viaje hacia la muerte, una fuga (el primer poema) inescapable. El cronotopo autobiográfico ya está desconstruido con el cronotopo inexorable del camino hacia la muerte, "navegando sin destino"), como dice en "Preludio".

El último de los cuatro poemas es "Canto final". Es un nuevo poema lírico, simbolista, que emana del flâneur de la vida. Todos estos textos se conectan con la mejor poesía del siglo de oro español, en su convergencia del tiempo, la vida, la muerte. Nuevamente la experiencia vital es un viaje "de una lucha sin fin" (la aventura central) donde el cronotopo autobiográfico y el del camino concluyen conjuntamente: "que a este paso tan rápido de muerte/ mucho antes de morir estaré muerto", en los versos finales, paradójicamente quevedianos.

Es posible que la omnipresencia de la muerte, a inicios de 1939, con el terremoto de Chillán, haya dejado una huella indeleble en estos poemas. La experiencia límite de ese verano, que convirtió Chillán en un cementerio, marca la escritura. De allí en adelante, la muerte, personificada, erotizada, relativizada, nunca más desaparecerá de la antipoesía. 


\section{DEL CRONOTOPO IDÍLICO COSTUMBRISTA A LO NACIONAL-POPULAR}

Pero con todo lo ya dicho no se acota todo lo publicado por Nicanor Parra en 1939, un año ciertamente decisivo en el camino de la modelación de la antipoesía, como se ve. Porque ese mismo año se publica una antología, titulada 8 nuevos poetas chilenos, editada por la Sociedad de Escritores de Chile (Santiago: Suplemento de la Revista SECH-Edición de la Universidad de Chile, 1939). Hay un Prólogo del propio Tomás Lago. Parra, que sólo lleva a la fecha cuatro años publicando, es (o será) el poeta más importante de todos (junto a Óscar Castro).

En esta antología que es la primera que hace justicia a la poesía de Parra figura también el poema "Nocturno" anteriormente publicado y aquí comentado anteriormente. También aparece "Canto cotidiano", ya publicado en revista Atenea, el mismo año. Para todos ellos hemos seguido la versión que aparece en Obras completas, volumen I. Son en total 13 poemas, que hay que analizar uno a uno, porque uno de ellos será el primer antipoema, el que inaugurará el sistema antipoético, aunque en una versión diferente a la que aparecerá en Poemas y antipoemas, en 1954. Pero los cambios no afectarán la índole esencial del poema, y menos de lo antipoético, que ya ha sido sorprendido parcialmente en "Sensaciones", los tres poemas de la Revista Nueva, No 1, de 1935. En mayor o menor grado, lo antipoético aparece, como se ha explicado, en varios de estos poemas (Jofré, 2010).

Parra ha afirmado en diversos lugares que todas estas composiciones que aquí se comentan son poemas de transición, que había elaborado casi simultáneamente en esta exploración de múltiples líneas. Es extraño conjugar en esta búsqueda lo folklórico experienciado (popular, criollo, chillanejo, de cultura baja) con el absurdo surrealista (alta cultura, europeo, cosmopolita, género alto letrado). Así que luego del romancero (popular, oral) y de lo histórico (también romance didáctico y patriótico, "nacionalizado") viene un "Esquinazo", título de un poema incorporado en esta antología (Parra, 2006: 647-654).

Esta línea tiene mucho de los discursos de sobremesa, del lenguaje cotidiano y coloquial, de un romance aclimatado, de lo folklórico y criollo, y por cierto, de la música nacional. Leonidas Morales recoge varios testimonios de que otros escritores apoyaban está línea parriana exploratoria (Pablo Neruda y Tomás Lago, entre otros). Lago mismo había, en cambio, discutido la línea surrealista absurda de los dos primeros relatos, más arriba comentados, por inapropiados. Hoy día la valoración sería ciertamente otra.

Este "esquinazo" es oralidad pública proclamada en la calle y es un poe- 
ma de unos trescientos versos. Se trata de un espacio social popular, callejero, como la invitación a viva voz a asistir a los circos. Quien recibe el mensaje no es un lector, sino que el narratario es un oyente. Es la praxis de la verbalidad oral lo que estructura el discurso. Este largo poema se organiza en torno al cronotopo idílico y costumbrista que valoriza positivamente lo popular. En ese sentido, "Esquinazo" es un camino fuera de lo sublime, del poema tradicional, descentrado, ironizador y prosaico. Y es un título que evoca inmediatamente un género discursivo.

$\mathrm{Y}$ se trata de aclarar, en un lenguaje huaso, con expresiones coloquiales, de géneros bajos, con una palabra que se refiere constantemente a ella misma. Quien habla es un chileno, lo que confirma lo nacional-popular tan importante en la definición de la cultura, según Gramsci. Están dados pues aquí los elementos conversacionales y orales de lo antipoético, con recurrencia a clichés coloquiales.

También en esta antología aparece el poema "La mano del joven muerto", estrictamente referida a la noche del terremoto de Chillán de enero de 1939. El cronotopo autobiográfico es decisivo aquí pues esa noche del 24 de enero Nicanor Parra conversaba con un joven chillanejo, Aliro Zumelzu, antes del terremoto, cerca de la Estación de trenes de Chillán. Luego se separan y cuando recorre Nicanor Parra, de 25 años de edad, la ciudad iluminada por los incendios, llega al centro, al diario La Ley y ve la mano de Zumelzu sobresaliendo de los escombros. El soneto posee la belleza de la línea de la poética clásica de la poesía española. Se construye sobre reiteraciones. Nuevamente está la presencia de la muerte, que tal como antes aparece como la blanca y fría nieve. Impecable soneto, a ratos lárico, a ratos lírico, vinculado a la poesía del siglo de oro español, y por ende, a una poética clásica.

Se va revelando que el gran desencadenante es la experiencia del terremoto de Chillán (7.0 Richter), y por ello la presencia omniabarcadora de la muerte que está testificada en todos los poemas publicados en 1939. Esto no había sido percibido en los estudios anteriores.

También en esta antología 8 nuevos poetas chilenos figura un poema titulado "Epopeya de Chillán". Al igual que antes, el título se refiere a un género literario, a un formato discursivo preciso, en este caso, la epopeya, que habla de hechos heroicos, de procesos grandiosos, colectivos, destacables. Este texto comienza con dos versos que dicen: "Que se levante el raudo viento azul del otoño/ que aquí no pasa nada que puramente todo". Estos son los opuestos que junta la antipoesía. El poema se organiza en torno a estos subjuntivos que buscan una aspiración y que señalan un deseo del hablante. 
El poema a Chillán es una alabanza de aldea y la reconstrucción de un locus amoenus. Está marcado por lo blanco de la muerte y la sangre. Es el lugar del cronotopo idílico costumbrista el que se manifiesta y no el espacio de la destrucción telúrica. El hablante se autodefine como corsario, como corazón, como anteriormente lo había hecho. Nuevamente vuelven los ángeles recurrentes de la poesía de Parra, como algo aquí positivo.

Chillán es el espacio del recuerdo para siempre, la identificación del personaje hablante con su espacio natal. Chillán es el centro del mundo. El poema concluye con una variación del inicio: "Que aquí se levante el fuego como un caballo de oro/ que aquí no pasa nada que puramente todo". Este es un paseo del flâneur por un Chillán ya ido pero aspirado, algo que es a la vez un deseo y un recuerdo.

En esta antología se han ido mostrando una serie de formas poéticas que evidencian la variedad de la exploración y búsqueda parriana en el período de Chillán, particularmente luego de la publicación de Cancionero sin nombre. Hay aquí en la antología 8 nuevos poetas chilenos, poesía lírica, esquinazos, cantares, poesía lárica, sonetos, epopeyas, autobiografías, cantos, églogas, testimonios.

La "Egloga de la infancia" es un poema lárico que se vuelca a los orígenes y al lugar natal. Nuevamente se recupera el idealizado espacio chillanejo como un locus amoenus, con un beatus ille que le acompaña. Ese tiempo de la infancia ya está ido pero persiste en el recuerdo. La infancia es "un lejano país". Re-emerge el ángel dos veces como un signo de lo inesperado y diferente. Un poema altamente quevediano, lo era también "La mano de un joven muerto".

La nueva alabanza de aldea recupera tanto elementos citadinos como de la naturaleza vista como paisaje. Nuevamente el hablante se visualiza a sí mismo como corazón, como estudiante soñador, como un niño. Es un espacio del "nunca jamás". Todos estos elementos muestran al poema con una factura clásica, digna del bucolismo del siglo de oro español, como aquí se ha reiterado, referido a otras composiciones.

El organizador interno del poema es otra vez el cronotopo autobiográfico, en conjunción con el cronotopo idílico natural. Aquí el flâneur prosigue su viaje psíquico recorriendo el largo camino de los recuerdos. Este es un illo tempore, un centro del mundo. El poema concluye inevitablemente con la presencia de la muerte, cama nevada, pero también con la antipoética imagen de "los insectos (que) me preparan", en un pequeño grotesco final.

El flâneur de provincia prosigue su itinerario, con el comienzo de "Rosa de amor": "Voy andando por el yelo/ por un callejón, a oscuras,/ para mí 
que voy perdido/". El paseante también, en su exploración, pasa por el extravío y la desorientación, atributos que podrían considerarse antipoéticos. Este poema tiene como dispositivo central el motivo del viaje, tan frecuente en Parra y el cronotopo autobiográfico, donde el yo interno narra una experiencia. El hablante se caracteriza como un corazón que busca, probablemente esa "rosa de amor" mencionada sólo en el título del poema. El hablante se siente desafortunado cuando dice: "Sé que nunca te hallaré", es decir, la búsqueda será infructuosa, como lo revelan los dos versos finales, con una forma subjuntiva que casi elimina la posibilidad del encuentro en el camino: "pueda ser que dé contigo/ pero bien lo sé que nunca".

El poema "Imagen de oro" está dedicado a Don Quijote y es un soneto acerca de "la más purísima persona". Las rosas y las palomas, que son objetos simbólicos frecuentes en estos poemas, están aquí marcando la vida de Don Quijote, hacia donde se extrapola la propia figura del hablante: yo aquí en Chillán, Don Quijote en la Mancha. Sin embargo, como en casi todos estos poemas, la voz (entendida como una hoja) de Don Quijote, "solo la muerte pudo marchitarla".

En "Imagen de mi padre" es obvia la presencia del cronotopo autobiográfico. Parra siempre ha insistido que la antipoesía estaba en la vida carnavalesca de su padre, que "hablaba casi cantando". El padre es el acompañante viajero, el amigo que inició al flâneur en los itinerarios por los campos. Está identificado con el agua, que es signo de transparencia, entrega, pureza y bondad, como atributo positivo también, de la naturaleza y de Chillán mismo.

Pero el final de la ciudad de Chillán y de todo es el mismo que tiene el padre, pues ahora es "amigo dulce dormido", que yace muerto como todo lo que ha sido poetizado en esta antología por Parra. La "imagen" del título es nuevamente un género o formato de la representación, como en "Imagen de oro", donde nuevamente está la palabra que organiza y clasifica el género discursivo del poema.

Lo mismo acontece con el título del poema "Cantares" que orienta al lector en una cierta dirección genérica. Nuevamente son el motivo del viaje y el tópico del flâneur los que arquitecturan la composición: "dicen que hay que caminar/ cada cual por su camino". Éste, como todos los poemas de esta antología, no han sido comentados ni analizados anteriormente. Como en el poema al padre, aparece la familia, en la filiación y la genealogía.

Además del cronotopo del camino, que integra experiencias y encuentros, está aquí nuevamente el cronotopo autobiográfico. Otra vez el motivo del extravío se manifiesta pues quien habla es un marino en tierra. Declara 
que "mi ley es la libertad", pero la condición es precaria, pues "el alma mía anda suelta/ y mi corazón perdido". Y eso es, como en "Rosa de amor", porque el amor se ha ido. Los cantares son un tipo de composición genéricoliteraria.

Hay otro poema, "Soneto", que aunque lleva también el nombre de una forma literaria, el lector se encuentra con cinco estrofas de cuatro versos, lo que ciertamente no es un soneto. Ésta es la ironía parriana, el desfase entre la forma y el contenido, uno de los principios de lo antipoético.

Se reitera el cronotopo autobiográfico, que es omnipresente, como el cronotopo del camino, ya que el hablante viene llegando de un viaje. Allí se ha concretado el cronotopo de la aventura. Se trata de un marino, y de un bandido, y un corazón, en reiterada autocaracterización. Otra vez los ángeles definen al hablante. Y como antes, la muerte cierra ya el presente, como cruel epílogo de todos estos poemas: "en un campo de nieve me he perdido/ y en él me quedaré, de blanco, muerto". En Parra la muerte no es negra, sino que blanca, como se ha visto.

Han quedado para el comentario final dos últimos poemas. Del primero, existe la certeza de que fue escrito antes del terremoto de 1939. Se trata de "Canto a la escuela", poema que fuera leído por el propio Nicanor Parra, entonces de 24 años de edad, frente a Gabriela Mistral, que lo doblaba en edad, tenía 49 años. Esto aconteció el 12 de mayo de 1938, en el Teatro Municipal de Chillán.

Según algunos críticos e historiadores, no estaba presupuestado que Parra leyera su poema; según otros, había sido invitado a participar en el homenaje a Gabriela Mistral. Todos concuerdan, sin embargo, en dos frases que le dijera la Mistral a Parra públicamente. Primero, que Parra era "un poeta ya formado", y segundo, que sería "el futuro poeta de Chile". Ninguna de estas dos expresiones se ha probado equivocada y ambas predijeron el destino del poeta y antipoeta de San Fabián de Alico.

Este poema, "Canto a la escuela", puede ser la continuación genuina de los poemas de "Sensaciones", de 1935, en el sentido de que no se va en la línea romancera de Cancionero sin nombre sino que se apega al cronotopo idílico costumbrista que implica una visión de una sociedad en un tiempo dado. La construcción nominativa, es decir, la abundancia de expresiones sustantivas es un signo a la vez del neorrealismo parriano y de la prosa de la antipoesía. El título, como otras veces, describe un género, un formato discursivo y envía al lector en una cierta dirección.

La capital de esa infancia narrada una y otra vez mediante el cronotopo autobiográfico es Chillán, denominado aquí "pueblo de niños" y "capital de 
cariño". Esto fue lo que escucho Gabriela Mistral: un entusiasmo parriano por lo local, por la infancia, y por lo pedagógico, todo ello desde un paradigma lingüístico que estaba en proceso de construcción en ese entonces, el de la antipoesía y que llevaba bastante avanzado.

El Liceo de Chillán, Chillán mismo, Chile, es un pueblo de niños, y esa nominación rebalsa el poema a cada momento con distintas variantes. Todos los recursos son aquí utilizados por el poeta, desde el surrealismo, el absurdo, lo biográfico, lo regionalista, lo clásico, para configurar un centro del mundo donde lo cósmico, la naturaleza, lo social y lo personal logran integrarse coherentemente.

El décimo tercer poema que comentar brevemente es "Sinfonía de cuna", y con él concluirá esta lectura del año 1939 en la poesía de Parra. Sigo la versión que aparece en Obras completas, I, 655-656, que asumo es una versión completa y cotejada con la edición de la antología de 1939 . He podido cotejar una media docena de diferencias de una versión a otra.

Nuestra argumentación la hemos desarrollado en forma oral anteriormente y confirma este poema como el primer antipoema, por sus características que se desplegarán a continuación, y porque es, en el tiempo, el primer poema que transita a Poemas y antipoemas, edición príncipe de 1954, a la primera sección de este poemario, en posición inicial, como poema portal.

Una sinfonía es un género musical de alto vuelo y una composición grandiosa, para gran orquesta, y etimológicamente es "lo que suena junto", o sea, implica una armonización de los elementos o instrumentos participantes. Suele tener tres o cuatro movimientos, momentos temporales de diferente ritmo o intensidad. Sin embargo, esta sinfonía es "de cuna", es decir, infantil, para bebés. Es algo naciente, primario, como lo es en efecto el antipoema. El título une pues dos opuestos, dos aspectos antagónicos, algo típico de la antipoesía, como la palabra antipoesía misma.

El primer movimiento sería el título. Y el segundo movimiento sería la introducción, constituida por los dos primeros versos. Inmediatamente se configura el cronotopo del camino, el motivo del viaje, la estructura del paseante. El espacio presentado es un parque inglés. Esta vez el flâneur tendrá un encuentro notable, absurdo, excepcional.

El tercer movimiento es mucho más extenso y está constituido por el encuentro e incluye todos los versos exceptuando los cuatro versos finales. Aparece aquí un ángel, pero es alguien muy diferente a todos los ángeles anteriores que han sido notados en otros poemas. Ocurre que el hablante que escribe en el poema lo hace en castellano, la misma lengua que habla 
el ángel, pero en el encuentro el hablante habla en francés (dos versos). El poema, hasta aquí se va armando intercultural e interlingüísticamente, con la presencia de lo inglés, lo castellano y lo francés.

Lo coloquial hace su entrada en una interpelación al narratario, directa, cuando dice "hay que ver señores/ cómo un ángel es". Allí está el planteamiento del enigma. El hablante no tiene ningún respeto por el ángel, a diferencia de las veces en que anteriormente aparecía como mención positiva en los otros poemas.

Hasta aquí en medio de una situación cotidiana ha emergido una realidad excepcional, pero esta superrealidad (el ángel) va a ser ironizada, parodiada, analizada y reconvertida. Una serie de operaciones se van a desatar. El ángel es frío, fijo, "feo como usted" (nueva interpelación al narratario y con ello al lector empírico), una expresión risueña, infantil y oral.

Lo irónico y sorpresivo vendrá a continuación, pues el ángel tiene plumas pero además un "duro cascarón de un pez". Este ser es algo grotesco que integra dos órdenes: lo aéreo y lo acuático. Es una mezcla híbrida. Algo kitsch, antipoético total. Hay además algo siniestro, "un sol de sangre". La impresión es tan grande frente a la nueva realidad, o mejor aún, a lo que hay bajo la superrealidad que se está revelando que el hablante se pone a hablar en francés y olvida las preguntas que quiere hacerle.

Hay pues una develación dentro de una develación. Ironía tras ironía, el hablante contribuye a la creación híbrida con un clavel azul y luego se despide cortésmente en inglés. El momento final es el cuarto movimiento, el retorno, cuando el hablante llega de vuelta a casa, a la normalidad, al mundo cotidiano. Se acaba la maravilla grotesca y lo absurdo excepcional. Se ironiza la aparición.

Los dos últimos versos de este primer antipoema, de 1939 (o antes) dicen: "Cuento aquí se acaba/ 1, 2 y 3". La palabra "cuento" puede ser el "el cuento aquí se acaba" (como sustantivo) o "yo cuento aquí se acaba" (como verbo). En ambos casos se trata de la historia que presenta la estructura narrativa y diegética que es este poema, la que finaliza. Esta es la conclusión o el epílogo, el cuarto movimiento o final de la sinfonía.

Y luego el verso final, que no está constituido por palabras sino que por números. Este es otro tipo de discurso. Una grafía diferente. Como diferente era ese "non lo vi muy bien", típico del español antiguo. Números que son como parte de la desaparición de lo mágico, la disolución final del primer antipoema, en un dos por tres.

Muchos de los trece poemas de la antología aquí comentada in extenso 
son verdaderos relatos, narraciones de historias versificadas. Son las experiencias del flâneur mental y físico que se integran en el camino psíquico y geográfico y que logran armar el mapa de un territorio llamado Chillán.

Producto de su estancia en Chillán comenzó a abrirse una posibilidad práctica y teórica, la de la antipoesía, buscando la claridad y la conjugación híbrida, en los años treinta, hasta llegar a 1938-1939, cuando realmente se concretó el primer antipoema.

Para concluir, podríamos decir que hubo en Chillán dos terremotos en 1939. Uno breve pero demoledor, y otro más permanente, que no fue otra cosa que la última pasantía de Parra en la ciudad, que concluyó el verano mismo del año '39.

\section{REFERENCIAS}

Bakhtin, M. M. (1981). "Forms of Time and of Chronotope in the Novel", en The Dialogic Imagination: Four Essays (pp. 84-258). Austin: University of Texas Press.

Roco del Campo, A. (1939). Panorama y color de Chile. Antología literario-descriptiva del paisaje y las costumbres nacionales. Santiago: Ercilla.

García Lorca, F. (1973 [1928]). Cancionero gitano. Buenos Aires: Losada.

Jofré, M. (2002). "El cristal empañado: Modernidad y postmodernidad en la obra de Nicanor Parra", Antiparra Productions. Santiago: División de Cultura, Ministerio de Educación, 131-137.

(2010). Parrafadas: Nicanor Parra, figura del Bicentenario. Santiago:

Fundación Imagen de Chile, 83 pp.

Parra, N. (1937). Cancionero sin nombre. Santiago: Nascimento.

(1939a). "Cantos cotidianos". Atenea No 168, tomo LVI, junio, 340-343. (1939b). "Cantos paralelos". Atenea No 174, tomo LVIII, diciembre, 286-290.

(1954). Poemas y antipoemas. Santiago: Nascimento.

(2006). Obras completas \& algo + (1935-1972), Vol. I. Barcelona: Galaxia Gutenberg, 1068.

Pfeiffer, E. (2014). La primera etapa de la poesía de Nicanor Parra (1935-1948): Hacia la revolución antipoética. Tesis de Magíster. Santiago: Universidad de Chile, 218 pp.

Sociedad de Escritores de Chile (1939). 8 nuevos poetas chilenos. Santiago: Universidad de Chile. 